\title{
Sulfur dioxide attenuates LPS-induced acute lung injury via enhancing polymorphonuclear neutrophil apoptosis
}

\author{
Hui-jie MA ${ }^{1}$, Xin-li HUANG ${ }^{2, *}$, Yan LIU ${ }^{3}$, Ya-min FAN ${ }^{2}$ \\ ${ }^{1}$ Department of Physiology, Hebei Medical University, Shijiazhuang 050017, China; ${ }^{2}$ Department of Pathophysiology, Hebei Medical \\ University, Shijiazhuang 050017, China; ${ }^{3}$ Department of Endocrinology, the Third Hospital of Hebei Medical University, Shijiazhuang \\ 050051, China
}

\begin{abstract}
Aim: We speculated that the enhanced apoptosis of polymorphonuclear neutrophil (PMN) might be responsible for the inhibition of PMN infiltration in the lung. This study was designed to investigate the effects of sulfur dioxide $\left(\mathrm{SO}_{2}\right)$ on $\mathrm{PMN}$ apoptosis in vivo and in vitro, which may mediate the protective action of $\mathrm{SO}_{2}$ on pulmonary diseases.

Methods: Acute lung injury (ALI) was induced by intratracheally instillation of lipopolysaccharide (LPS, $100 \mu \mathrm{g} / 100 \mathrm{~g}$, in $200 \mu \mathrm{L}$ saline) in adult male SD rats. $\mathrm{SO}_{2}$ solution $(25 \mu \mathrm{mol} / \mathrm{kg})$ was administered intraperitoneally 30 min before LPS treatment. The rats were killed $6 \mathrm{~h}$ after LPS treatment. Lung tissues were collected for histopathologic study and $\mathrm{SO}_{2}$ concentration assay. Bronchoalveolar lavage fluid (BALF) was collected for the measurement of PMN apoptosis. For in vitro experiments, rat peripheral blood PMNs were cultured and treated with LPS $(30 \mathrm{mg} / \mathrm{L})$ and $\mathrm{SO}_{2}(10,20$ and $30 \mu \mathrm{mol} / \mathrm{L})$ for $6 \mathrm{~h}$, and apoptosis-related protein expression was detected by Western blotting, and apoptosis rate was measured with flow cytometry.

Results: LPS treatment significantly reduced the $\mathrm{SO}_{2}$ concentrations in the lung tissue and peripheral blood, as compared with the control group. Pretreatment with $\mathrm{SO}_{2}$ prevented LPS-induced reduction of the $\mathrm{SO}_{2}$ concentration in the lung tissue and peripheral blood. LPS treatment significantly reduced PMN apoptosis both in vivo and in vitro, which could be prevented by the pretreatment with $\mathrm{SO}_{2}$. The protein levels of caspase-3 and Bax was significantly increased, but Bcl-2 was decreased by the pretreatment with $\mathrm{SO}_{2}$, as compared with LPS administration alone.

Conclusion: $\mathrm{SO}_{2}$ plays an important role as the modulator of PMN apoptosis during LPS-induced ALI, which might be one of the mechanisms underlying the protective action of $\mathrm{SO}_{2}$ on pulmonary diseases.
\end{abstract}

Keywords: acute lung injury; bronchoalveolar lavage fluid (BALF); lipopolysaccharide; $\mathrm{SO}_{2}$; apoptosis; polymorphonuclear granulocyte

Acta Pharmacologica Sinica (2012) 33: 983-990; doi: 10.1038/aps.2012.70; published online 16 Jul 2012

\section{Introduction}

Acute lung injury (ALI) induced by sepsis and its severe form, acute respiratory distress syndrome (ARDS), are still major causes of morbidity and mortality in clinics ${ }^{[1]}$. It is generally accepted that ALI is an excessive, uncontrolled inflammatory response within the lung ${ }^{[2]}$. Inhibiting different stages of ALI with drugs or therapy, along with enhancing the body's own resistance, would delay or mitigate lung injury and minimize the mortality associated with $\mathrm{ALI}^{[1,2]}$.

Gas transmitters such as nitric oxide (NO), carbon monoxide (CO) and hydrogen sulfide $\left(\mathrm{H}_{2} \mathrm{~S}\right)$ play important roles in both

\footnotetext{
* To whom correspondence should be addressed.

E-mail mm564300@sina.com

Received 2012-02-01 Accepted 2012-05-11
}

physiological and pathological conditions ${ }^{[3-7]}$. In recent years, interest has been directed towards another naturally occurring gas, sulfur dioxide $\left(\mathrm{SO}_{2}\right) . \mathrm{SO}_{2}$ was previously considered a toxic gas, but it has been subsequently shown to be produced endogenously during the metabolism of sulfur-containing amino acids ${ }^{[8]}$. $\mathrm{SO}_{2}$ was also previously considered a risk factor for respiratory and cardiovascular disease ${ }^{[9]}$. Recently, studies have shown that $\mathrm{SO}_{2}$ plays important pathophysiologic roles during many disease processes, including the attenuation of monocrotaline-induced pulmonary hypertension, the inhibition of hypoxic pulmonary vascular structural remodeling, protection against isoproterenol-induced myocardial injury, and the increase of myocardial antioxidant capacity ${ }^{[10-12]}$. However, the effects of $\mathrm{SO}_{2}$ on ALI and its mechanisms are poorly understood. 
Our previous study revealed that the administration of $\mathrm{SO}_{2}$ derivatives alleviated the degree of LPS-induced ALI and reduced the number of polymorphonuclear granulocytes (PMN) in bronchoalveolar lavage fluid (BALF), whereas $\mathrm{SO}_{2}$ administered alone did not result in functional and morphological changes in rat lungs ${ }^{[13]}$. PMNs are important inflammatory cells that are implicated in excessive inflammatory responses $^{[2,14]}$. Studies have shown that there exists an inhibition and delay in PMN apoptosis in lung tissue during ALI. The delay in apoptosis may lead to the prolonged release of PMN products and direct tissue injury, which then participate in the development of $\mathrm{ALI}^{[15]}$. Therefore, the inhibition of PMN apoptosis leads to inflammation and lung tissue damage, whereas the enhancement of PMN apoptosis may reduce lung inflammation and damage ${ }^{[16]}$. We speculated that the enhancement of PMN apoptosis might be responsible for the inhibition of PMN infiltration in the lung, thereby mediating the protective effect of $\mathrm{SO}_{2}$. The aim of this study was to investigate the role of PMN apoptosis in the protective effect of $\mathrm{SO}_{2}$ in LPS-induced ALI.

\section{Materials and methods Induction of ALI}

All experiments were approved by the Animal Ethics Committee of Hebei Medical University and were carried out in accordance with established guiding principles for animal research. Adult male Sprague Dawley (SD) rats (250-300 g) provided by the Experimental Animal Center of Hebei Province (Shijiazhuang, China) were randomly divided into four groups: control group, $\mathrm{SO}_{2}$ group, LPS group and LPS plus $\mathrm{SO}_{2}$ group. The rats were anesthetized via intraperitoneal injections of pentobarbital $(50 \mathrm{mg} / \mathrm{kg})$. The control rats were instilled intratracheally with $200 \mu \mathrm{L}$ normal saline. LPS-treated animals received $200 \mu \mathrm{L}$ LPS (Escherichia coli 055:B5; SigmaAldrich Co, St Louis, MO, USA) by intratracheal instillation (100 $\mu \mathrm{g} / 100 \mathrm{~g}$ of body weight, dissolved in $200 \mu \mathrm{L}$ saline). For the LPS group, LPS was evenly sprayed into both lungs using a microsprayer and laryngoscope for rats (Penn-Century Inc, Philadelphia, PA, USA). For the $\mathrm{SO}_{2}$ group, $25 \mu \mathrm{mol} / \mathrm{kg}$ $\mathrm{SO}_{2}$ saline solution was administered intraperitoneally. For the LPS plus $\mathrm{SO}_{2}$ group, $25 \mu \mathrm{mol} / \mathrm{kg} \mathrm{SO}_{2}$ saline solution was administered intraperitoneally 30 min before LPS treatment.

For $\mathrm{SO}_{2}$ solution preparation, pure $\mathrm{SO}_{2}$ gas (purity: $99.99 \%$, Beijing He-Pu-Bei-Fen Gas Company, Ltd, Beijing, China) was used in this study. The $\mathrm{SO}_{2}$ solution was freshly prepared before each experiment by bubbling saline with pure $\mathrm{SO}_{2}$ gas, and it was then diluted to achieve a solution containing the desired $\mathrm{SO}_{2}$ concentration according to the method described by Zhang et al ${ }^{[17]}$.

\section{Histopathologic analyses and ratio of lung wet weight to dry weight $(\mathrm{Rw} / \mathrm{d})$}

For histopathologic analyses, excised lung tissues were fixed and then embedded in paraffin and routinely stained with hematoxylin and eosin. Inflammation and alveolar edema were graded as none, mild, moderate, or severe. The level of lung injury was determined based on the degree of cellular and protein exudation and tissue hemorrhage and was assigned a score between 0 (normal) and 3 (severely damaged), as previously described by Kristof et $a l^{[18]}$. The severity of lung injury was scored by pulmonologists who were blind to the treatment. Briefly, 10 fields were randomly selected from three lung tissue sections per rat and were examined under a microscope at $200 \times$ magnification. The degree (or score) of cellular and protein exudation and tissue hemorrhage per rat were individually determined by adding the scores from 10 randomly selected fields. The total lung injury score per rat was determined as the sum of three individual scores for alveolar cellularity, protein exudation and tissue hemorrhage.

A portion of lung tissue was weighed and placed into an $80^{\circ} \mathrm{C}$ oven to be dried completely, and the $\mathrm{Rw} / \mathrm{d}$ was then calculated.

\section{Measurement of $\mathrm{SO}_{2}$ concentrations in lung tissue and blood}

The right lung samples were homogenized and immediately subjected to sample preparation according to the method established by Sun et al and Mitsuhashi et al ${ }^{[11,19]}$. Lung or blood samples $(100 \mu \mathrm{L})$ were mixed with $70 \mu \mathrm{L}$ of $0.212 \mathrm{~mol} / \mathrm{L}$ sodium borohydride in $0.05 \mathrm{~mol} / \mathrm{L}$ Tris- $\mathrm{HCl}(\mathrm{pH} \mathrm{8.5)}$ and incubated at room temperature for $30 \mathrm{~min}$. The samples were then mixed with $10 \mu \mathrm{L}$ of $70 \mathrm{mmol} / \mathrm{L}$ monobromobimane in acetonitrile. After incubation for $10 \mathrm{~min}$ at $42^{\circ} \mathrm{C}, 40 \mu \mathrm{L}$ of 1.5 $\mathrm{mmol} / \mathrm{L}$ perchloric acid solution was added to the mixture, followed by vortex mixing. The protein precipitates were removed by centrifugation at $12400 \times g$ for $10 \mathrm{~min}$ at room temperature. The supernatant was immediately neutralized by adding $10 \mu \mathrm{L}$ of $2 \mathrm{mmol} / \mathrm{L}$ Tris ( $\mathrm{pH} \mathrm{3.0).} \mathrm{It} \mathrm{was} \mathrm{then} \mathrm{gen-}$ tly mixed and centrifuged again at $12400 \times \mathrm{g}$ for $10 \mathrm{~min}$. Ten microliters of the neutralized supernatant was injected into an HPLC column (Hitachi 655-A11 system, Japan). All sample preparation procedures were completed within $2 \mathrm{~h}$ after tissue sample homogenization. Serum sulfite was determined using reversed phase HPLC with fluorescence detection. The samples were resolved on a $4 \mathrm{~mm} \times 250 \mathrm{~mm}$ C8 reversed phase column (5 $\mu \mathrm{m}$ packing, GL Science, Tokyo, Japan). The column was equilibrated with methanol/acetic acid/water (5.00:0.25:94.75, by volume, $\mathrm{pH} 3.4$ ) and developed with a gradient of methanol at a flow rate of $0.8 \mathrm{~mL} / \mathrm{min}$ as follows: $0-5$ min, $30 \mathrm{~mL} / \mathrm{L}$; 5-13 $\mathrm{min}, 30-500 \mathrm{~mL} / \mathrm{L}$; 13-30 min, 350-620 $\mathrm{mL} / \mathrm{L}$; 30-31 min, 620-1000 mL/L; 31-39 min, $1000 \mathrm{~mL} / \mathrm{L}$; 39-40 $\mathrm{min}, 1000-30 \mathrm{~mL} / \mathrm{L}$; and 40-46 min, $30 \mathrm{~mL} / \mathrm{L}$. Sulfitebimane was detected by excitation at $390 \mathrm{~nm}$ and emission at $472 \mathrm{~nm}$ with the use of a cutoff filter and eluted at $45 \mathrm{~mL} / \mathrm{L}$ of methanol concentration.

\section{Isolation and purification of PMNs in BALF}

The isolation and purification of BALF were performed after the rats were killed. BALF was collected and centrifuged, and the sediment was collected and then resuspended in RPMI1640 medium containing $10 \%$ calf serum. The cell suspension was cultured in the incubator $\left(37^{\circ} \mathrm{C}, 5 \% \mathrm{CO}_{2}\right)$ for $2 \mathrm{~h}$. The 
attached cells in the culture dish were discarded and suspension cells were collected for further purification. BALF neutrophils were isolated using a two-step Percoll gradient (1080 $\mathrm{g} / \mathrm{mL}$ followed by $1090 \mathrm{~g} / \mathrm{mL}$ ) centrifugation method. The purity of the PMNs isolated by gradient centrifugation was greater than $98 \%$ (identified using Wright's staining), and the cell survival rate was more than 95\% (identified using trypan blue). PMN apoptosis was further detected by acridine orange/ethidium bromide (AO/EB, Sigma-Aldrich Co, St Louis, MO, USA) staining and flow cytometry (FCM).

\section{PMN apoptosis by AO/EB staining and FCM}

A fluorescent assay with $\mathrm{AO} / \mathrm{EB}$ double staining was used ${ }^{[20]}$ to display the morphological alterations of apoptotic PMNs in BALF. The BALF PMNs were suspended in PBS ( $\mathrm{pH} 7.2)$ and aliquoted for the staining procedure. One microliter of the dye mixture $(100 \mathrm{mg} / \mathrm{mL} \mathrm{AO}$ and $100 \mathrm{mg} / \mathrm{mL}$ EB in distilled water) was mixed with $9 \mathrm{~mL}$ of cell suspension on a clean microscope slide and examined immediately by fluorescence microscopy at 400× magnification. A minimum of 500 cells was counted in every sample. The percentage of apoptotic cells was defined as the average number of apoptotic cells per 100 counted cells.

FCM was performed as previously described ${ }^{[21]}$. The BALF PMNs were double-labeled with Annexin V-FITC/PI. Approximately 5000 cells from each sample were measured by flow cytometry with an excitation wavelength of $488 \mathrm{~nm}$ and emission wavelengths of $515 \mathrm{~nm}$ and $610 \mathrm{~nm}$. Annexin $\mathrm{V}$-positive cells were considered viable apoptotic cells (early apoptotic cells), propidium iodine (PI)-positive cells were defined as necrotic cells, and Annexin V and PI double positive cells were defined as non-viable apoptotic cells (late apoptotic cells). Because PMNs were absent from the BALF of the control group, we replaced BALF with peripheral blood in the analysis of the control group according to Feng et $a l^{[16]}$.

\section{Preparation of rat lymphocyte separating medium}

The separating medium was prepared according to the method described by Feng et al ${ }^{[16]}$. Solution A (9\% Ficoll solution): 3.4 parts normal saline was added to 1 part $40 \%$ Ficoll and mixed thoroughly. Solution B (34\% diatrizoate meglumine solution): $24.71 \mathrm{~mL}$ normal saline was added to $20 \mathrm{~mL}$ $76 \%$ diatrizoate meglumine solution and mixed thoroughly. Ten parts of solution A and 5.5 parts of solution B were mixed thoroughly. A Baumé hydrometer was used to measure the specific density of the mixture. The specific density of the solution was adjusted to 1.084 by adding solution A or solution B. A G6 fritted-glass filter was applied to filtrating sterilization. The lymphocyte separating medium was stored at $4^{\circ} \mathrm{C}$ in dark. Ficoll and sodium diatrizoate hydrate were purchased from Sigma-Aldrich Co (St Louis, MO, USA).

\section{Isolation and purification of peripheral blood PMNs}

Heparinized venous blood (4 mL per rat) was collected by jugular vein catheterization. Density gradient centrifugation was applied to isolate and purify the PMNs in peripheral blood using lymphocyte separating medium. The cell suspension and the thin film layer (containing mononuclear cells) were discarded. The sediment was collected, and erythrocyte lysis buffer was applied to remove the red blood cells. After the sediment was washed with D-Hanks' buffer three times and then centrifuged $(2000 \mathrm{r} / \mathrm{min} \times 10 \mathrm{~min}$ each), the PMN sediment was resuspended at $5 \times 10^{6}$ cells/mL in RPMI-1640 (containing $10 \%$ calf serum) in preparation for further treatment.

\section{Peripheral blood PMN cell culture and evaluation of PMN apoptosis by FCM}

Peripheral blood PMNs were cultured in RPMI-1640 medium at $37^{\circ} \mathrm{C}$ in $5 \% \mathrm{CO}_{2}$ and treated with $30 \mathrm{mg} / \mathrm{L} \mathrm{LPS}$ and different concentration of $\mathrm{SO}_{2}\left(10,20\right.$, and $\left.30 \mu \mathrm{mol} / \mathrm{L} \mathrm{SO}_{2}\right)$ in vitro for $6 \mathrm{~h}$ for the detection of apoptosis-related protein expression using the Western blotting method. To determine the rate of apoptosis, PMNs were cultured for $24 \mathrm{~h}$ and then submitted to FCM. After culture, the cell suspension was centrifuged, washed and resuspended for western blotting analysis and FCM. FCM for the peripheral blood PMNs was performed as described above for the BALF cells.

\section{Western blotting analysis of apoptosis-related protein expression in peripheral blood PMNs}

To measure the Caspase-3, Bax, and Bcl-2 protein expression levels by western blotting, cellular proteins were extracted from the peripheral blood PMNs of rats, as previously described $^{[22]}$. The PMNs were pelleted and lysed in $1 \times$ Laemmli-buffer [2\% (wt/vol) SDS, 6\% (vol/vol) 2-mercaptoethanol, $10 \%(\mathrm{vol} / \mathrm{vol})$ glycerol, and a trace amount of bromophenol blue in $200 \mathrm{mmol} / \mathrm{L}$ Tris- $\mathrm{HCl}, \mathrm{pH} 7.5]$. The samples were immediately heated for $5 \mathrm{~min}$ at $100^{\circ} \mathrm{C}$. The concentration of the proteins was determined using the BCA method. Samples containing $50 \mu \mathrm{g}$ of total protein were subjected to SDS-PAGE on gels containing $12 \%$ ( $w t / v o l)$ acrylamide and then transferred to a polyvinylidene difluoride membrane. Nonspecific binding sites were blocked with TBST $(40 \mathrm{mmol} / \mathrm{L}$ Tris, $\mathrm{pH}$ 7.6, $300 \mathrm{mmol} / \mathrm{L} \mathrm{NaCl}, 0.1 \%$ Tween 20 ) containing 5\% nonfat dry milk for $12 \mathrm{~h}$ at $4^{\circ} \mathrm{C}$. The membranes were incubated in rabbit polyclonal anti-rat antibodies to Caspase-3, Bax, and Bcl-2 (1:500, Santa Cruz Biotechnology, Santa Cruz, CA, USA) and a mouse anti-rat antibody to $\beta$-actin (diluted 1:10000 in $0.01 \mathrm{~mol} / \mathrm{L}$ PBS, Santa Cruz Biotechnology, Santa Cruz, CA, USA). After the membranes were washed three times in TBST, they were then incubated in a 1:5000 dilution of HRP-conjugated goat anti-rabbit IgG (Amersham-Pharmacia Biotech, UK). After again washing with TBST, the membranes were incubated with horseradish peroxidase-conjugated streptavidin (diluted 1:4000 in $0.01 \mathrm{~mol} / \mathrm{L}$ PBS, Zymed, USA) for $1 \mathrm{~h}$ at $37^{\circ} \mathrm{C}$. The immunoreactions were visualized using an ECL detection kit (Pierce, Thermo Scientific, USA). The X-ray film was scanned by an image documentation system (Labworks Inc, USA). The integral optical density (IOD) of each band was measured using a gel image analysis system (Alpha Image 2200, Alpha, USA). The changes in the relative expression of Caspase-3, Bax, and Bcl-2 were represented by the ratio of the 
band's IOD of Caspase-3, Bax, and Bcl-2 compared to $\beta$-actin.

\section{Statistical analysis}

All data were expressed as the mean \pm SD. Comparisons between groups were performed using analysis of variance (ANOVA) followed by the Student Newman-Keuls test using SPSS 13.0 statistical analysis software. $P$ values less than 0.05 were considered statistically significant.

\section{Results}

\section{Effects of $\mathrm{SO}_{2}$ on LPS-induced lung damage}

In control rats and rats given $\mathrm{SO}_{2}$ alone rats, few infiltrating PMN cells were observed, and there was no evidence of hemorrhage or edema (Figure $1 \mathrm{Aa}$ and $1 \mathrm{Ab}$ ). In contrast to the control group, patching hemorrhage was observed at $6 \mathrm{~h}$ after LPS infusion. Typical pathologic alterations induced by LPS were also observed, including the accumulation of inflammatory cells in the alveolar space, interalveolar septum thickening, edema of the lung interstitium and alveoli, interstitial and intra-alveolar hemorrhage, and even some alveolus atelectasis and fusion (Figure 1Ac). Meanwhile, compared with the control group, LPS treatment led to a significant increase in the total lung injury score and the $\mathrm{Rw} / \mathrm{d} 6 \mathrm{~h}$ after LPS treatment $(P<0.01$, Figure $1 \mathrm{~B}$ and $1 \mathrm{C}) . \mathrm{SO}_{2}$ pretreatment may partially protect the lung tissue from damage induced by LPS (Figure 1 $\mathrm{Ad})$ and may prevent the increased total lung injury score and $\mathrm{Rw} / \mathrm{d}(P<0.05$, Figure $1 \mathrm{~B}$ and $1 \mathrm{C}) . \mathrm{SO}_{2}$ alone had no significant effect on total lung injury score and lung weight $(P>0.05$, Figure 1B and 1C).

\section{Changes in $\mathrm{SO}_{2}$ concentration in the different treatment groups}

Compared with the control group, the $\mathrm{SO}_{2}$ concentration in the lung tissue and peripheral blood decreased at $6 \mathrm{~h}$ after LPS treatment. Pretreatment with $\mathrm{SO}_{2}$ significantly elevated the $\mathrm{SO}_{2}$ concentration compared with that of the LPS group $(P<0.05$, Figure 2). Our results indicate that the reduction of endogenous $\mathrm{SO}_{2}$ production may participate in the development of ALI and exogenously supplemented $\mathrm{SO}_{2}$ may ameliorate lung injury.

\section{PMN apoptosis observed by AO/EB staining and FCM}

$\mathrm{AO} / \mathrm{EB}$ staining indicated that alveolar macrophages were predominant, but PMNs were absent in the BALF of control rats (Figure 3Aa). Apoptotic PMNs were found in the BALF of LPS-treated rats, but only a few early apoptotic PMNs, which were characterized by strong nuclear green fluorescence staining, were observed (Figure $3 \mathrm{Ab}$ ). Compared with the control group, LPS treatment also led to a significant reduction in PMN apoptosis in BALF, as determined by FCM $(P<0.05$, Figure $3 \mathrm{~B})$. However, a large number of apoptotic PMNs were found in the lungs of $\mathrm{SO}_{2}$-treated rats, which were characterized by condensed and fragmented nuclear staining by orange EB (Figure 3Ac). The percentage of apoptotic PMN cell determined by FCM was also significantly increased in the LPS plus $\mathrm{SO}_{2}$ group compared with the group treated only with LPS $(P<0.05$, Figure $3 \mathrm{~B})$.

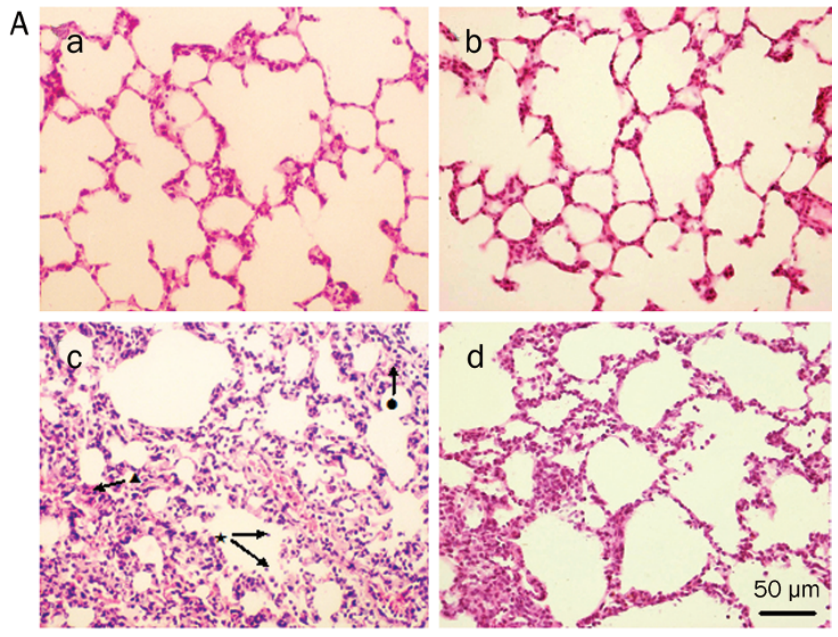

B

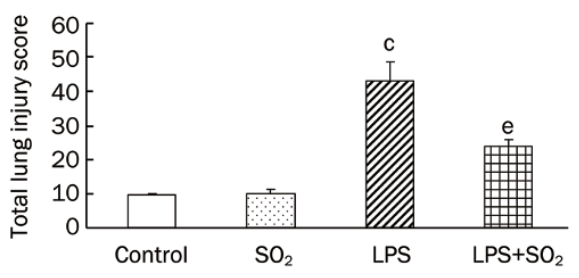

C

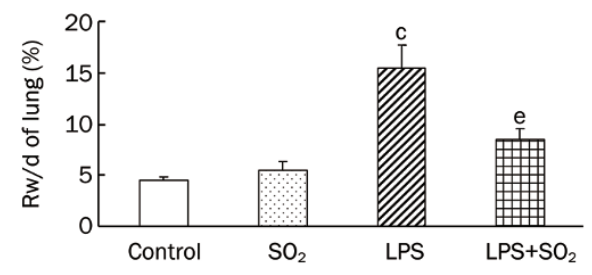

Figure 1. Morphological and lung Rw/d changes in lungs at $6 \mathrm{~h}$ after the induction of $\mathrm{ALI}$ with or without $\mathrm{SO}_{2}$ pretreatment. (A) Morphological changes in the lung by $\mathrm{H} \& \mathrm{E}$ staining. a) Control group with normal lung morphology; b) $\mathrm{SO}_{2}$ administration alone with lung morphology similar to the control group; c) Six hours after induction of LPS-induced ALI we observed patching hemorrhage and inflammatory cell accumulation in the alveolar space $(\star)$, interalveolar septum thickening $(\bullet)$, edema of lung interstitium and alveoli, interstitial and intra-alveolar hemorrhage $(\boldsymbol{\Delta})$, and even some alveolus atelectasis and fusion; d) $\mathrm{SO}_{2}$ pretreatment ameliorated the lung injury induced by LPS. Scale bar, $50 \mu \mathrm{m}$. (B) Effect of $\mathrm{SO}_{2}$ on the total lung injury score. (C) Effect of $\mathrm{SO}_{2}$ on lung $\mathrm{Rw} / \mathrm{d}$ $6 \mathrm{~h}$ after intratracheal instillation of LPS. Data are presented as the mean \pm SD ( $n=7$ in each group). ${ }^{c} P<0.01$ compared with the control group; ${ }^{\mathrm{e}} P<0.05$ compared with the LPS group.

In the peripheral blood, the changes of apoptotic PMNs were similar to those observed in BALF. The percentage of apoptotic PMNs was reduced in the LPS treatment group, whereas the percentage increased in the $\mathrm{SO}_{2}$ plus LPS group relative to the group treated with LPS alone $(P<0.05$ or $P<0.01$, Figure 3C).

\section{Effect of $\mathrm{SO}_{2}$ on apoptosis-related protein expression}

Compared with the control group, LPS treatment significantly decreased Caspase-3 (Figure 4) and Bax (Figure 5) protein expression in the peripheral blood PMNs of rats, whereas 
A

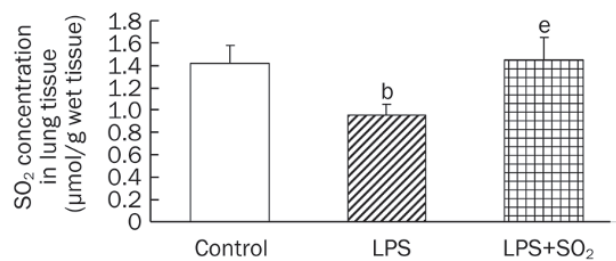

B

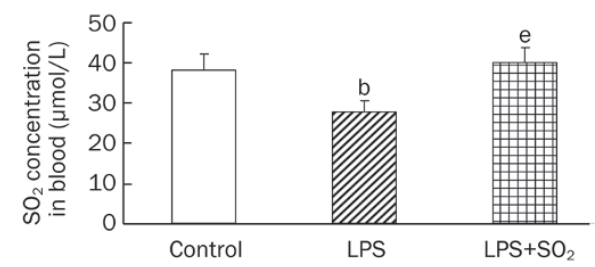

Figure 2. Changes in $\mathrm{SO}_{2}$ concentration in the lung tissue $(\mathrm{A})$ and peripheral blood (B) $6 \mathrm{~h}$ after intratracheal instillation of LPS. Data are presented as the mean $\pm S D$ ( $n=6$ in each group). ${ }^{b} P<0.05$ compared with the control group; ${ }^{e} P<0.05$ compared with the LPS group.

Bcl-2 (Figure 6) protein levels increased. The effects of LPS were significantly reversed by the administration of $\mathrm{SO}_{2}$ in a concentration-dependent manner $(P<0.05$ or $P<0.01$, Figure 4 , 5 and 6).

\section{Discussion}

In the present study, we found that $\mathrm{SO}_{2}$ enhanced PMN apoptosis in LPS-induced ALI. We also found that the $\mathrm{SO}_{2}$ content decreased in ALI, and exogenously administered $\mathrm{SO}_{2}$ significantly increased the $\mathrm{SO}_{2}$ levels in the lung tissue compared with the LPS group. These results suggest that the downregulation of endogenous $\mathrm{SO}_{2}$ results in the inhibition and delay of PMN apoptosis during ALI might be involved in the pathogenesis of LPS-induced ALI, which may be reversed by $\mathrm{SO}_{2}$. Moreover, our results showed that the $\mathrm{SO}_{2}$ levels in control plasma was $38.12 \pm 4.13 \mu \mathrm{mol} / \mathrm{L}$, so the $\mathrm{SO}_{2}$ concentration selected in our study was within a physiological concentration range.

ALI is a life-threatening disease that often leads to acute hypoxemic respiratory failure with intensive pulmonary inflammation, accompanied by various cellular and molecular changes $^{[23,24]}$. The pathogenesis of endotoxin-induced ALI remains obscure and has not yet been fully elucidated. However, it is generally accepted that PMNs have well characterized effects on the pathogenesis of LPS-induced lung injury, and PMN accumulation in the lung is the key pathological basis for the development of $\mathrm{ALI}^{[2,14]}$. PMNs are vital to the body's defense against infections. However, the uncontrolled release of their formidable array of toxic substances may inflict damage on the surrounding tissues and propagate inflammatory responses, leading to tissue scarring and destruction. Normally, PMNs are removed by apoptosis to limit their activation ${ }^{[25]}$. When PMNs die by apoptosis, they retain their granular contents but lose chemotactic and secretory responsiveness. These PMNs are recognized and phagocytosed by
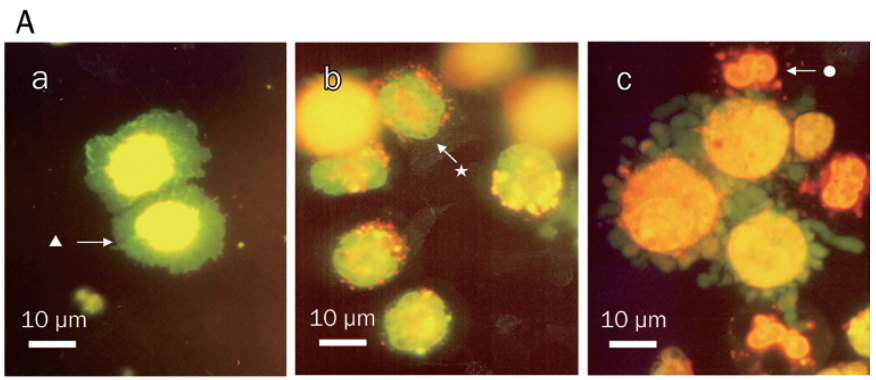

B

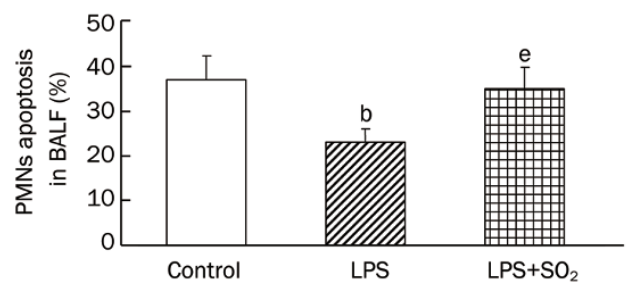

C

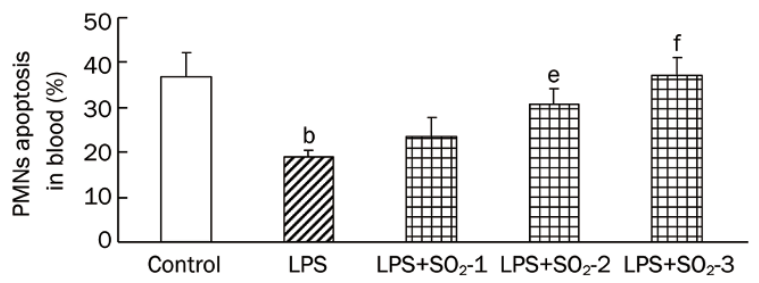

Figure 3. PMN apoptosis determined by AO/EB-staining and FCM at $6 \mathrm{~h}$ after induction of $\mathrm{ALI}$ with or without $\mathrm{SO}_{2}$ pretreatment. (A) PMN apoptosis determined by AO/EB-staining in BALF. a) No apoptotic PMNs, only alveolar macrophages $(\boldsymbol{\Delta})$, were observed in the lungs of control rats; b) Only a few early apoptotic PMNs $(\star)$ were observed (strong nuclear green fluorescence staining) in the LPS group. c) A large number of apoptotic PMNs $(\bullet)$ were found in the lungs of rats pretreated with $\mathrm{SO}_{2}$ before LPS administration $\left(\mathrm{LPS}+\mathrm{SO}_{2}\right.$ ) rat. Condensed and fragmented nuclear were stained by orange EB and apoptotic PMNs in $\mathrm{LPS}+\mathrm{SO}_{2}$ group. Scale bar, $10 \mu \mathrm{m}$. (B) The percentage of apoptotic PMN cells in BALF, as determined by flow cytometry. Control, control group; LPS, LPS administration group; $\mathrm{LPS}+\mathrm{SO}_{2}$ refers to $\mathrm{SO}_{2}$ pretreatment before LPS administration. (C) The percentage of apoptotic PMNs in the peripheral blood, as determined by flow cytometry. $\mathrm{SO}_{2}-1$, pretreatment with $10 \mu \mathrm{mol} / \mathrm{L} \mathrm{SO}_{2} ; \mathrm{SO}_{2}-2$, pretreatment with $20 \mu \mathrm{mol} / \mathrm{L} \mathrm{SO}_{2}$; $\mathrm{SO}_{2}-3$, pretreatment with $30 \mu \mathrm{mol} / \mathrm{L}$ $\mathrm{SO}_{2}$. Because PMNs were absent in the BALF of the control group, we replaced BALF with peripheral blood for the control group. Data are presented as the mean $\pm S D$ ( $n=7$ in each group). ${ }^{b} P<0.05$ compared with the control group; ${ }^{e} P<0.05,{ }^{\text {f }} P<0.01$ compared with the LPS group.

macrophages. Thus, by down-regulating the potentially harmful PMN functions and triggering their clearance by phagocytes, apoptosis provides a mechanism for the safe removal of inflammatory cells ${ }^{[25]}$. Moreover, studies in recent years have shown that the inhibition and delay of PMN apoptosis occurs in the lung tissue during ALI, which leads to the prolonged release of PMN products and direct tissue injury ${ }^{[15]}$. Inhibiting the delay in apoptosis of PMN may ameliorate the lung injury. $\mathrm{SO}_{2}$ and its derivatives were previously considered systemic 

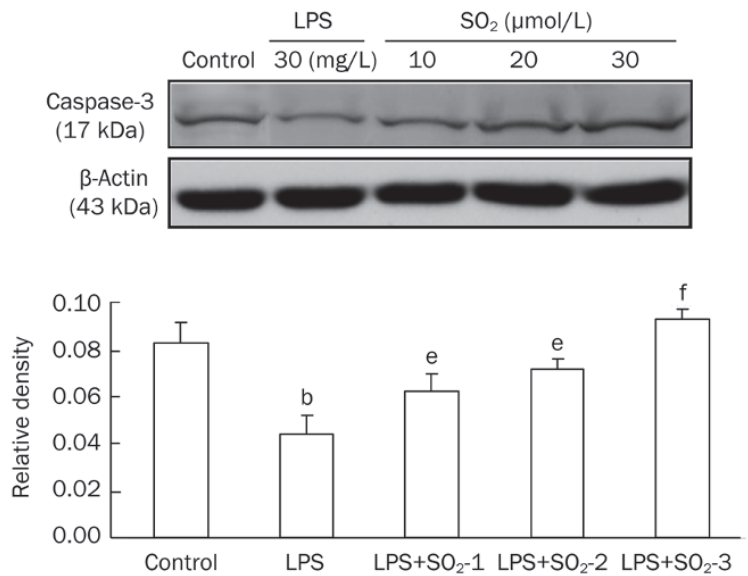

Figure 4. Protein expression of Caspase-3 extracted from the peripheral blood PMNs of rats in the different groups. The upper panels are Western blots, and the lower panels are summaries of the densitometric analysis of Caspase-3 protein expression in the different groups. Control, control group; LPS, LPS administration group; LPS $+\mathrm{SO}_{2}-1$, pretreatment with 10 $\mu \mathrm{mol} / \mathrm{L} \mathrm{SO} \mathrm{S}_{2}$ before LPS administration; LPS $+\mathrm{SO}_{2}-2$, pretreatment with 20 $\mu \mathrm{mol} / \mathrm{L} \mathrm{SO} \mathrm{S}_{2}$ before LPS administration; LPS $+\mathrm{SO}_{2}-3$, pretreatment with 30 $\mu \mathrm{mol} / \mathrm{L} \mathrm{SO} \mathrm{S}_{2}$ before LPS administration. Data are shown as the mean $\pm \mathrm{SD}$ ( $n=6$ rats in each group). ${ }^{b} P<0.05$ compared with the control group; ${ }^{\mathrm{e}} P<0.05,{ }^{\mathrm{f}} P<0.01$ compared with the LPS group.
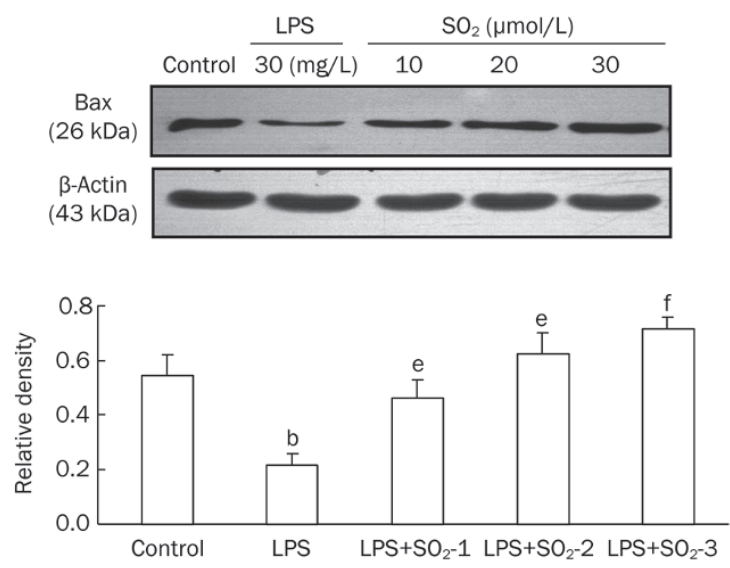

Figure 5. Protein expression of Bax extracted from the peripheral blood PMNs of rats in the different groups. The upper panels are Western blots, and the lower panels are summaries of the densitometric analysis of Bax protein expression in the different groups. Control, control group; LPS, LPS administration group; LPS $+\mathrm{SO}_{2}-1$, pretreatment with $10 \mu \mathrm{mol} / \mathrm{L} \mathrm{SO}_{2}$ before LPS administration; LPS $+\mathrm{SO}_{2}-2$, pretreatment with $20 \mu \mathrm{mol} / \mathrm{L} \mathrm{SO}_{2}$ before LPS administration; LPS $+\mathrm{SO}_{2}-3$, pretreatment with $30 \mu \mathrm{mol} / \mathrm{L} \mathrm{SO}_{2}$ before LPS administration. Data are shown as the mean \pm SD $(n=6$ rats in each group). ${ }^{b} P<0.05$ compared with the control group; ${ }^{e} P<0.05,{ }^{f} P<0.01$ compared with the LPS group.

toxic agents that can cause many types of toxic effects, such as chromosomal aberrations, micronuclei, sister-chromatid exchanges ${ }^{[19,26-29]}$, gene mutations ${ }^{[30]}$, lipid peroxidative dam-
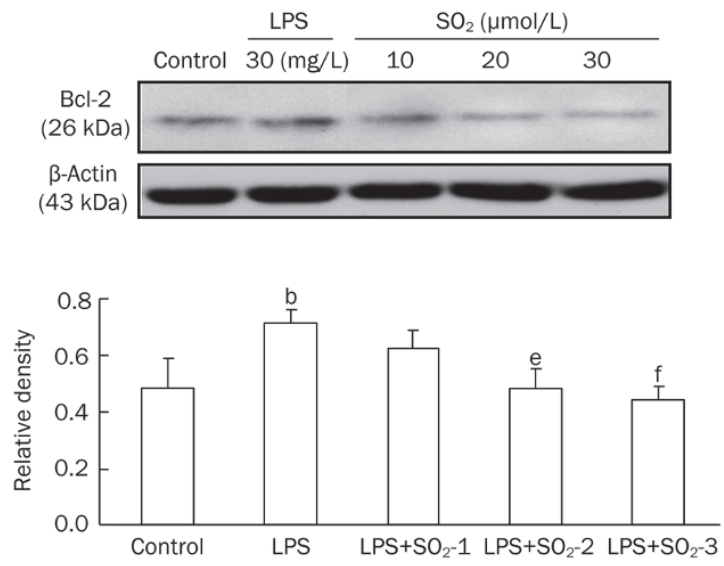

Figure 6. Protein expression of Bcl-2 extracted from the peripheral blood PMNs of rats in the different groups. The upper panels are Western blots, and the lower panels are summaries of the densitometric analysis of Bcl-2 protein expression in the different groups. Control, control group; LPS, LPS administration group; LPS $+\mathrm{SO}_{2}-1$, pretreatment with $10 \mu \mathrm{mol} / \mathrm{L} \mathrm{SO}_{2}$ before LPS administration; LPS $+\mathrm{SO}_{2}-2$, pretreatment with $20 \mu \mathrm{mol} / \mathrm{L} \mathrm{SO}_{2}$ before LPS administration; LPS $+\mathrm{SO}_{2}-3$, pretreatment with $30 \mu \mathrm{mol} / \mathrm{L} \mathrm{SO}_{2}$ before LPS administration. Data are shown as the mean $\pm S D(n=6$ rats in each group). ${ }^{\mathrm{b}} P<0.05$ compared with the control group; ${ }^{\mathrm{e}} P<0.05,{ }^{\mathrm{f}} P<0.01$ compared with the LPS group.

$\operatorname{age}^{[31]}$, DNA damage ${ }^{[32,33]}$, and changes in some enzyme activities $^{[34]}$ in multiple organs in mice and rats. Studies have also indicated that $\mathrm{SO}_{2}$ inhalation can also cause gene expression changes and alter cytokine levels in the rat lung ${ }^{[35]}$. However, increasing attention has recently been paid to understanding its physiological roles in biological cells and its role in the pathology of various diseases. Endogenous $\mathrm{SO}_{2}$ was found to be generated during cysteine metabolism in many types of mammalian cells. It was found that the $\mathrm{SO}_{2}$ derivatives as physiological condition are a neuron modulator in rat hippocampal neurons ${ }^{[36]}$ and dorsal root ganglion (DRG) neurons ${ }^{[37-39]}$ and can also function as cardiovascular modulators in cardiomyocytes ${ }^{[40-42]}$ by affecting their ion channels. Studies have also showed that $\mathrm{SO}_{2}$ and its derivatives can cause a significant decrease in rat blood pressure in vivo and the vasorelaxation of rat blood vessel rings in vitro ${ }^{[30,43]}$. However, as a biological mediator, its role in ALI needs to be clarified.

In our previous study, we demonstrated that $\mathrm{SO}_{2}$ derivatives play an important role in the development LPS-induced $\mathrm{ALI}^{[4]}$. Our results showed that the administration of $\mathrm{SO}_{2}$ derivatives to LPS-treated rats reduced the lung weight/body weight ratio, PMN number, ICAM-1 expression and IL-1, IL-6 and IL-10 levels, and alleviated the degree of ALI. In the present study, we found that treatment with a physiological concentration of $\mathrm{SO}_{2}$ solution can attenuate the inflammatory response and reverse the increased lung $\mathrm{Rw} / \mathrm{d}$ induced by LPS treatment. However, there were no significant differences in the above parameters between the rats treated with $\mathrm{SO}_{2}$ alone and the control rats. The results indicate that the concentration used in our experiment had no toxic effects on 
the lung. More interestingly, it has been reported that $\mathrm{SO}_{2}$ can induce the apoptosis of hippocampal neurons ${ }^{[4]}$ and enhance the apoptosis of smooth muscle cells in spontaneously hypertensive rats $(\mathrm{SHRs})^{[45]}$. As of yet, there are no reports indicating whether a low dose of $\mathrm{SO}_{2}$ can induce PMN apoptosis while ameliorating lung injury.

The present study provides new evidence that there is a certain correlation between $\mathrm{SO}_{2}$ and PMN apoptosis, which was inhibited and delayed in LPS-induced acute lung injury. LPS challenge overwhelmingly inhibited the apoptosis of PMNs in the BALF and peripheral blood in ALI rats, indicating that an inhibition and delay of PMN apoptosis during LPS-induced ALI. FCM revealed that the changes in the percentage of apoptotic PMNs were similar in the peripheral blood and BALF. These results showed that PMNs emigrate from blood vessels to the lung and remain highly active in releasing their noxious contents, thus triggering lung tissue damage. The living PMNs adhere to endothelial cells and release inflammatory mediators and destructive toxic substances, damaging blood vessels and surrounding tissues ${ }^{[2,15]}$. On the other hand, secondary necrotic PMNs release toxic products such as active oxygen, free radicals and lysosomal enzyme, causing tissue damage $^{[14,15,46]}$. The accidents may result in systemic inflammatory response syndrome (SIRS) or even multiple organ dysfunction syndrome (MODS) $)^{[15]}$. $\mathrm{SO}_{2}$ treatment could enhance the apoptosis of PMNs in the BALF of rats, which could indicate that $\mathrm{SO}_{2}$ can play an important role as a modulator in PMN apoptosis during LPS-induced acute lung injury.

Because we discovered that a physiological concentration of $\mathrm{SO}_{2}$ can improve lung injury by promoting PMN apoptosis, we need to further explore the mechanism by which it promotes apoptosis. The mammalian Bcl-2 family of apoptosisassociated proteins consists of members that inhibit apoptosis (Bcl-2, Bcl-xL, Mcl-1, A1, etc) and others that induce apoptosis (Bax, Bak, Bad, Bcl-xs, Bik, etc), and the balance between proapoptotic and anti-apoptotic members determines the fate of the cells in many systems. The Bcl-2 family regulates apoptosis by controlling the activity of caspases, the executioners of apoptosis, via the release of cytochrome $c$ from mitochon$\mathrm{dria}^{[22]}$. Caspases are a family of cysteine proteases that exist in normal cells as inactive enzymes. They are activated by sequential proteolytic events that lead to the degradation or functional alteration of cellular proteins, which contributes to cell death, characterized by the typical apoptotic morphology. Caspase- 3 activation is one of the main requirements for the execution phase of apoptosis ${ }^{[25]}$. To further investigate the molecular mechanisms of PMN apoptosis, we assessed Caspase-3, Bax, and Bcl-2 protein expression in PMNs. In LPS-induced ALI, PMNs emigrated from the blood vessels to the lung, and the reactions of PMNs in BALF and the peripheral blood were similar in our study. Because alveolar macrophages were predominant but PMNs were absent in normal rat BALF, we substituted BALF PMNs with peripheral blood PMNs for our apoptosis-related protein expression study in vitro. After co-incubation with different doses of $\mathrm{SO}_{2}(10,20$, and $30 \mu \mathrm{mol} / \mathrm{L})$, the expression of apoptosis-related genes changed. The present study indicated that $\mathrm{SO}_{2}$ modulates the expression of apoptosis-related proteins and then enhances PMN apoptosis, thereby alleviating LPS-induced ALI. Performing the research in vitro obviated the influence of the complex internal environment and directly reflected the impact of $\mathrm{SO}_{2}$ on PMN apoptosis.

In summary, our study demonstrates that physiological concentrations of $\mathrm{SO}_{2}$ play an important role as a modulator in the inhibition and delay of PMN apoptosis during LPS-induced ALI. The modulation of $\mathrm{SO}_{2}$ may be one of the important mechanisms for LPS-induced ALI. $\mathrm{SO}_{2}$-targeted treatment may bring new light to the prevention and treatment of LPSinduced ALI. This study may provide a basis for the development of drugs about increasing endogenous $\mathrm{SO}_{2}$ in the body and provide new ideas for the clinical treatment of ALI.

\section{Acknowledgements}

This research program was supported by the National Natural Science Foundation of China (№ 81070050 and 30800440) and the Natural Science Foundation of Hebei Province (No C2007000830, C2008001040, and H2012206009).

\section{Author contribution}

Xin-li HUANG designed the study; Hui-jie MA, Yan LIU, and Ya-min FAN performed the research; Yan LIU analyzed the data; and Hui-jie MA wrote the paper.

\section{References}

1 Kneyber MC, Markhorst DG. Management of acute lung injury and acute respiratory distress syndrome in children: a different perspective. Crit Care Med 2009; 37: 3191-2.

2 Fujishima S, Aikawa N. Neutrophil-mediated tissue injury and its modulation. Intensive Care Med 1995; 21: 277-85.

3 Arias-Diaz J, Villa N, Hernandez J, Vara E, Balibrea JL. Carbon monoxide contributes to the cytokine-induced inhibition of surfactant synthesis by human type II pneumocytes. Arch Surg 1997; 132: 1352-60.

4 Huang XL, Ma HJ, Zhou XH, Fan YM, Xian XH, Cao H. Effect of exogenous hydrogen sulfide on polymorphonuclear neutrophil accumulation in acute lung injury rat induced by lipopolysaccharides and its mechanism. Zhongguo Ying Yong Sheng Li Xue Za Zhi 2010; 26 : 477-80.

5 Huang XL, Zhou XH, Zhou JL, Ding $\mathrm{CH}$, Xian XH. Role of polymorphonuclear neutrophil in exogenous hydrogen sulfide attenuating endotoxin-induced acute lung injury. Sheng Li Xue Bao 2009; 61: 356-60.

6 Connelly L, Palacios-Callender M, Ameixa C, Moncada S, Hobbs AJ. Biphasic regulation of NF-kappa $B$ activity underlies the pro- and antiinflammatory actions of nitric oxide. J Immunol 2001; 166: 3873-81.

7 Morisaki H, Katayama T, Kotake $\mathrm{Y}$, Ito M, Handa M, Ikeda Y, et al. Carbon monoxide modulates endotoxin-induced microvascular leukocyte adhesion through platelet-dependent mechanisms. Anesthesiology 2002; 97: 701-9.

8 Stipanuk MH. Metabolism of sulfur-containing amino acids. Annu Rev Nutr 1986; 6: 179-209.

9 Yun $\mathrm{Y}$, Hou L, Sang N. $\mathrm{SO}_{2}$ inhalation modulates the expression of proinflammatory and pro-apoptotic genes in rat heart and lung. J Hazard Mater 2011; 185: 482-8. 
10 Jin HF, Du SX, Zhao X, Wei HL, Wang YF, Liang YF, et al. Effects of endogenous sulfur dioxide on monocrotaline-induced pulmonary hypertension in rats. Acta Pharmacol Sin 2008; 29: 1157-66.

11 Sun Y, Tian Y, Prabha M, Liu D, Chen S, Zhang R, et al. Effects of sulfur dioxide on hypoxic pulmonary vascular structural remodeling. Lab Invest 2010; 90: 68-82.

12 Liang Y, Liu D, Ochs T, Tang C, Chen S, Zhang S, et al. Endogenous sulfur dioxide protects against isoproterenol-induced myocardial injury and increases myocardial antioxidant capacity in rats. Lab Invest 2011; 91: 12-23.

13 Huang XL, Zhou JL, Zhou XH, Xian XH, Ding $\mathrm{CH}$. Ameliorative effects of exogenous sulfur dioxide on lipopolysaccharide-induced acute lung injury in rats. Sheng Li Xue Bao 2009; 61: 499-503.

14 Mecklenburgh K, Murray J, Brazil T, Ward C, Rossi AG, Chilvers ER. Role of neutrophil apoptosis in the resolution of pulmonary inflammation. Monaldi Arch Chest Dis 1999; 54: 345-9.

15 Lee WL, Downey GP. Neutrophil activation and acute lung injury. Curr Opin Crit Care 2001; 7: 1-7.

16 Feng Y, Yang Q, Xu J, Qian G, Liu Y. Effects of HMGB1 on PMN apoptosis during LPS-induced acute lung injury. Exp Mol Pathol 2008; 85: 214-22.

17 Zhang Q, Meng Z. The vasodilator mechanism of sulfur dioxide on isolated aortic rings of rats: Involvement of the $\mathrm{K}^{+}$and $\mathrm{Ca}^{2+}$ channels. Eur J Pharmacol 2009; 602: 117-23.

18 Kristof AS, Goldberg P, Laubach V, Hussain SN. Role of inducible nitric oxide synthase in endotoxin-induced acute lung injury. Am J Respir Crit Care Med 1998; 158: 1883-9.

19 Mitsuhashi H, Ikeuchi H, Yamashita S, Kuroiwa T, Kaneko Y, Hiromura $\mathrm{K}$, et al. Increased levels of serum sulfite in patients with acute pneumonia. Shock 2004; 21: 99-102.

20 Baskic D, Popovic S, Ristic P, Arsenijevic NN. Analysis of cycloheximide-induced apoptosis in human leukocytes: fluorescence microscopy using annexin V/propidium iodide versus acridin orange/ ethidium bromide. Cell Biol Int 2006; 30: 924-32.

21 Vermes I, Haanen C, Steffens-Nakken H, Reutelingsperger C. A novel assay for apoptosis. Flow cytometric detection of phosphatidylserine expression on early apoptotic cells using fluorescein labelled Annexin V. J Immunol Methods 1995; 184: 39-51.

22 Weinmann P, Gaehtgens P, Walzog B. Bcl-XI- and Bax-alpha-mediated regulation of apoptosis of human neutrophils via caspase-3. Blood 1999; 93: 3106-15.

23 Chen HI, Yeh DY, Liou HL, Kao SJ. Insulin attenuates endotoxininduced acute lung injury in conscious rats. Crit Care Med 2006; 34 : 758-64.

24 Ritter C, da Cunha AA, Echer IC, Andrades M, Reinke A, Lucchiari $\mathrm{N}$, et al. Effects of $\mathrm{N}$-acetylcysteine plus deferoxamine in lipopolysaccharide-induced acute lung injury in the rat. Crit Care Med 2006; 34: 471-7.

25 Dyugovskaya L, Polyakov A, Lavie P, Lavie L. Delayed neutrophil apoptosis in patients with sleep apnea. Am J Respir Crit Care Med 2008; 177: 544-54.

26 Meng ZQ, Zhang LZ. Observation of frequencies of lymphocytes with micronuclei in human peripheral blood cultures from workers in a sulphuric acid factory. Environ Mol Mutagen 1990; 15: 218-20.

27 Meng ZQ, Zhang LZ. Chromosomal aberrations and sister-chromatid exchanges in lymphocytes of workers exposed to sulphur dioxide. Mutat Res 1990; 241: 15-20.
28 Meng Z, Zhang B. Polymerase chain reaction-based deletion screening of bisulfite (sulfur dioxide)-enhanced gpt-mutants in $\mathrm{CHO}$ AS52 cells. Mutat Res 1999; 425: 81-5.

29 Meng Z, Geng H, Bai J, Yan G. Blood pressure of rats lowered by sulfur dioxide and its derivatives. Inhal Toxicol 2003; 15: 951-9.

30 Meng $Z$, Zhang $\mathrm{H}$. The vasodilator effect and its mechanism of sulfur dioxide-derivatives on isolated aortic rings of rats. Inhal Toxicol 2007; 19: 979-86.

31 Meng Z, Liu Y. Cell morphological ultrastructural changes in various organs from mice exposed by inhalation to sulfur dioxide. Inhal Toxicol 2007; 19: 543-51.

32 Meng Z, Zhang B, Ruan A, Sang N, Zhang J. Micronuclei induced by sulfur dioxide inhalation in mouse bone-marrow cells in vivo. Inhal Toxicol 2002; 14: 303-9.

33 Meng Z, Qin G, Zhang B, Bai J. DNA damaging effects of sulfur dioxide derivatives in cells from various organs of mice. Mutagenesis 2004; 19: 465-8.

34 Zhang B, Nie A, Bai W, Meng Z. Effects of aluminum chloride on sodium current, transient outward potassium current and delayed rectifier potassium current in acutely isolated rat hippocampal CA1 neurons. Food Chem Toxicol 2004; 42: 1453-62.

35 Meng Z, Qin G, Zhang B. DNA damage in mice treated with sulfur dioxide by inhalation. Environ Mol Mutagen 2005; 46: 150-5.

36 Meng Z, Zhang B. Induction effects of sulfur dioxide inhalation on chromosomal aberrations in mouse bone marrow cells. Mutagenesis 2002; 17: 215-7.

37 Fujishima S, Morisaki H, Ishizaka A, Kotake Y, Miyaki M, Yoh K, et al. Neutrophil elastase and systemic inflammatory response syndrome in the initiation and development of acute lung injury among critically ill patients. Biomed Pharmacother 2008; 62: 333-8.

$38 \mathrm{Du}$ Z, Meng Z. Modulation of sodium currents in rat dorsal root ganglion neurons by sulfur dioxide derivatives. Brain Res 2004; 1010: $127-33$.

39 Du Z, Meng Z. Sulfur dioxide derivatives modulation of high-threshold calcium currents in rat dorsal root ganglion neurons. Neurosci Lett 2006; 405: 147-52.

40 OIman MA, White KE, Ware LB, Simmons WL, Benveniste EN, Zhu $\mathrm{S}$, et al. Pulmonary edema fluid from patients with early lung injury stimulates fibroblast proliferation through IL-1 beta-induced IL-6 expression. J Immunol 2004; 172: 2668-77.

41 Nie A, Meng Z. Sulfur dioxide derivative modulation of potassium channels in rat ventricular myocytes. Arch Biochem Biophys 2005; 442: 187-95.

42 Nie A, Meng Z. Study of the interaction of sulfur dioxide derivative with cardiac sodium channel. Biochim Biophys Acta 2005; 1718: 67-73.

43 Meng Z, Li Y, Li J. Vasodilatation of sulfur dioxide derivatives and signal transduction. Arch Biochem Biophys 2007; 467: 291-6.

44 Yun Y, Li H, Li G, Sang N. SO $\mathrm{SO}_{2}$ inhalation modulates the expression of apoptosis-related genes in rat hippocampus via its derivatives in vivo. Inhal Toxicol 2010; 22: 919-29.

45 Zhao X, Jin HF, Tang CS, Du JB. Effects of sulfur dioxide, on the proliferation and apoptosis of aorta smooth muscle cells in hypertension: experiments with rats. Zhonghua Yi Xue Za Zhi 2008; 88: 1279-83.

46 Chopra M, Reuben JS, Sharma AC. Acute lung injury: apoptosis and signaling mechanisms. Exp Biol Med (Maywood) 2009; 234: 361-71. 